\title{
QUADRILHA JUNINA E CIDADE, MERCADO E BELEZA DA OBRA
}

\author{
LUCIANA CHIANCA
}

\begin{abstract}
RESUMO
Nas festas juninas, o universo rural guarda centralidade simbólica, articulando imagens e símbolos do rural através de uma memória da migração que abarca os citadinos em sua experiência cotidiana e na festa. Uma dança exclusiva deste período - a quadrilha, mobiliza uma trama que dá sentido à cidade como obra (H. Lefebvre, 1970), projetando seus protagonistas numa participação crítica e consciente enquanto dialogam com a política, o espetáculo, o mercado e a presença crescente das mídias nas festas juninas.
\end{abstract}

\author{
PALAVRAS CHAVE \\ Festa junina; Festa; Quadrilha; Cidade.
}

\section{QUADRILLES, CITY, MARKET AND THE BEAUTY OF THE WORK}

\begin{abstract}
At Brazilian urban festivals around popular saints, namely around Saint John's Day, the rural universe articulates images and symbols of the rural through a memory of the migration that encompasses the citizens in our everyday experience and at the party.The dance called Quadrilha mobilizes a plot that gives meaning to city as a work (H. Lefebvre: 1970) by projecting its protagonists in a critical and conscious involvement, as they dialogue with the politics, spectacle, the market, and the increasing participation of commercial media in the process.
\end{abstract}

\section{KEYWORDS}

Feasts; St. John's quadrilles; St. John's feasts; Urban, St. John's.

\section{CUADRILLA JUNINA Y CIUDAD, MERCADO Y BELLEZA DE LA OBRA}

\section{RESUMEN}

En las fiestas juninas, el universo rural guarda centralidad simbólica, articulando imágenes y símbolos del rural a través de una memoria de la migración que abarca a los ciudadanos en su experiencia cotidiana y en la fiesta. Una danza exclusiva de este período (San juan) - la cuadrilla, moviliza una trama que da sentido a la ciudad como obra (H. Lefebvre, 1970), proyectando sus protagonistas en una participación crítica y consciente a la vez que dialogan con la política, el espectáculo, el mercado y los medios de comunicación, cada año más presentes en las fiestas juninas.

\section{PALABRAS CLAVE}

Fiesta junina; Fiesta; Cuadrilla; Ciudad, San Juan. 


\section{QUADRILHAS DE LA SAINT JEAN ET LA VILLE, LE MARCHÉ ET LA BEAUTÉ DE L'FUVRE}

\section{RÉSUMÉ}

Aux feux de la Saint Jean brésiliens l'univers rural a une centralité symbolique, articulant des images et des symboles du rural à travers un souvenir de la migration qui englobe les citoyens dans leur expérience quotidienne et dans celle de la fête. Une danse exclusive de cette période - la quadrilha - mobilise un réseau qui donne sens à la ville en tant qu'œuvre (H. Lefebvre, 1970), en projetant leurs protagonistes dans une participation critique et consciente avec la politique, le spectacle, le marché et les médias, chaque année plus présente aux nuits de fête.

\section{MOTS-CLÉS}

Feux de la Saint Jean; Fête; Quadrille; Ville; La Saint Jean. 


\section{QUADRILHA JUNINA E CIDADE, MERCADO E BELEZA DA OBRA}

"Une voie s'ouvre encore, celle de la société urbaine et de l'humain comme oeuvre dans cette société qui serait oeuvre et non produit". (Henri Lefebvre, 1967, p.30)

Destacando os diferentes suportes históricos, sócio-culturais e as tensões presentes nas múltiplas possibilidades de vivências na festa junina, sabemos que nele o universo rural mantém uma centralidade simbólica (Chianca, 2013a; Albernaz, 2009). Então, como esta festa contribui para articular tal realidade à imaginação urbana, enquanto inaugura um tempo/espaço de abertura para o futuro permitindo também o reforço das estruturas sociais cotidianas?

Analisando tais festas como um momento expressivo da vida social urbana, buscamos dar relevo ao "investimento afetivo" de que falava Henri Lefebvre (1970, p. 198), ou seja; "o processo pelo qual um indivíduo ou um grupo valoriza um objeto, investe nele sua energia afetiva, suas capacidades de ação, tenta fazer dele algo à sua imagem, com sua marca, tenta fazer dele sua obra." . Рara H. Lefebvre, "a própria cidade é uma obra" (1991, p. 04), cuja beleza decorre da potência do afeto investido nessa dimensão criadora que se apropria, transformando "em seu bem algo do exterior, de modo que podemos falar de um tempo ou de um espaço urbano apropriados ao grupo que construiu a cidade" (Lefebvre, 1970, p. 198)2.

As festas juninas revelam um interstício de possibilidades criativas ao qual Henri Lefebvre foi sensivel, analisando especialmente as conexões entre o rural e o urbano nos processos de urbanização e industrialização da sociedade capitalista. Neste artigo, este feixe de interpretações dialoga com outros processos contemporâneos, notadamente a agência e a espetacularização dessas festas.

Em muitas cidades do Brasil, encontramos grupos praticando uma dança característica do período junino: as quadrilhas juninas ${ }^{3}$. Muito numerosas e quase impossíveis de recensear ${ }^{4}$, as quadrilhas produzem uma expressão estética e artística que demanda um grande investimento financeiro, de tempo, articulação de apoios diversos, muita disposição física e psicológica. Pesquisando as festas juninas em bairros socialmente desfavorecidos da

\footnotetext{
${ }^{1}$ Tradução livre do francês.

${ }^{2}$ Tradução do autor.

${ }^{3}$ A quadrilha é uma dança de origem palaciana trazida ao Brasil pela família imperial portuguesa no século XIX. Convertida em dança popular ao longo do XX, ela continua muito praticada no século XXI.

${ }^{4}$ Segundo Menezes Neto (2009, p. 22) os dados sobre elas “mudam muito rapidamente. A cada ano, quadrilhas se acabam, outras se formam, algumas param as atividades por um período e depois as retomam, acontecem dissidências, fusões, etc." Destacamos que neste artigo trataremos mais especificamente de grupos quadrilhas de competição, que são grupos produzidos com o objetivo de participar (e vencer) campeonatos voltados para esta dança. A titulo informativo em 2016, 39 grupos de quadrilhas foram selecionados para o XXIX Festival de Quadrilhas de Natal, entre cômicas,
} 
cidade de Natal, fomos surpreendidos com estes grupos de quadrilhas, onde se destaca a primazia do investimento afetivo - do qual fala H. Lefebvre - sobre todos os condicionantes há pouco citados.

Percebemos que este elemento subjetivo (o afeto) se objetiva nas escolhas estéticas e coreográficas, representações teatrais, acompanhamento musical, cenários, vestimentas, maquiagens e técnicas corporais que emergem em suas apresentações, constituindo uma "obra" no sentido lefrèbvriano, que opera com base nos projetos e agências dos grupos.

\section{QUADRILHAS DE COMPETIÇÃO: O MERCADO E A OBRA}

Como outras partes da cidade de Natal, Mãe Luiza é um bairro que possui diversas quadrilhas juninas. Ele está encravado num setor que é alvo de grande especulação imobiliária, situado numa posição geográfica privilegiada; embora não seja uma periferia espacial, a relação da cidade com o bairro de Mãe Luíza é conduzida por uma percepção valorativa e enfatizada pelos poderes públicos e mídias locais, que o consideram como uma periferia social e cultural ${ }^{5}$.

Como alhures, ali encontramos quadrilhas improvisadas, ou seja, ocorrendo de modo espontâneo, sem preparação, organização ou necessidade de um público. Outras são ensaiadas diversas vezes e apresentadas num momento e local previamente acertado, comportando expectadores: são as quadrilhas de espetáculo privativo, que ocorrem em escolas, locais de trabalho, associações, etc. Às vezes essa apresentação não se limita a um público restrito, e alcança um grande público, ocorrendo num quadro de visibilidade ampliada, como um shopping center, um ginásio de esportes ou grande estacionamento, muitas vezes com transmissão televisiva e visando a obtenção de um prêmio num concurso. Os grupos que se preparam para esse tipo de desafio são conhecidos como quadrilhas de competição, atuando em festivais ou concursos envolvendo competições com premiações materiais ou simbólicas (Menezes Neto, 2009; Chianca 2006; 2013). A diversidade de motivações e modos de organizar uma quadrilha dificulta um recenseamento das quadrilhas, inclusive porque muitas delas - especialmente as improvisadas - têm um ciclo efêmero.

Diferentemente das quadrilhas de improviso e dos grupos de espetáculo privativo, as quadrilhas de competição são um jogo sério onde todos investem muito recursos, energia, sonhos e projetos, mobilizando-se para vencer os concursos, numa démarche que envolve rivalidades e disputas internas e externas em troca de visibilidade, dinheiro e reputação:

\footnotetext{
${ }^{5}$ O centro e a periferia como categorias nativas, sendo Mãe Luiza considerada "periférica" por sua situação de precariedade sócio-econômica. As suas designações na cidade de Natal e a própria categoria bairro são mais bem discutidas em Chianca (2008). 


\begin{abstract}
"Assim como na teoria da prática, a vida social, sob a perspectiva dos jogos sérios, é vista como algo ativamente jogado, voltado para metas e projetos culturalmente constituídos e envolvendo tanto práticas de rotina como ações intencionalizadas. Mas a perspectiva dos jogos sérios [...] permite-nos dar nitidez a formas mais complexas de relações sociais, especialmente relações de poder, e a dimensões mais complexas da subjetividade dos atores sociais - particularmente, para os fins deste texto, as que envolvem 'intencionalidade' e agência'"(Ortner, 2007, p. 45-46).
\end{abstract}

Os concursos podem envolver concorrentes de uma mesma cidade, estado ou de todo pais- como os da CONFEBRAQ (Confederação Brasileira de Entidades de Quadrilhas Juninas) ${ }^{6}$ - mas em geral são promovidos pelos poderes públicos (prefeituras municipais ou governos estaduais), e iniciativas do poder privado, como órgãos de comunicação, especialmente as emissoras de televisão.

Um grupo de quadrilha pode atingir mais de 100 pessoas (entre dançarinos e suportes), organizando uma vasta trama de relações que privilegia as relações de amizade, vínculos familiares e relações de vizinhança, numa rede que cotidianamente parece se concentrar neste círculo restrito. Por ocasião da festa junina essa rede se estende, podendo constituir alianças entre famílias próximas, grupos do bairro ou setores de habitação, vindo a revelar novos contornos das redes cotidianas desses habitantes. Outros apoios acorrem de outros bairros da cidade e instituições coletivas, sejam elas do âmbito público ou privado, como associações, clubes, escolas, prefeituras e representantes municipais, comerciantes e imprensa (Menezes Neto, 2009; Chianca, 2009; 2008). Estas conexões articulam as diversas demandas que se impõem ao longo do ano, como empréstimos de ônibus para transporte, verba para compra de material (desde tecidos a equipamentos de som), lanche para os dançarinos, aluguel de roupas e acessórios, entre outros.

Tanto a perenidade de um grupo quanto sua presença nos concursos e festivais está diretamente condicionada à sua capacidade de articular e gerir esses recursos materiais e simbólicos - para garantir sua visibilidade junto à totalidade do campo festivo da cidade, e para custear pelo menos uma parte dos custos de uma montagem anual do grupo, cuja vestimenta mais simples pode custar mais de mil reais (U\$ 300 aproximadamente). Tais despesas são proibitivas para a grande maioria dos seus participantes, em geral estudantes ou trabalhadores urbanos.

Mesmo a vitória num concurso importante não garante a autonomia financeira de um grupo no ano seguinte: a título de exemplo, o maior prêmio do I Festival de Quadrilhas do Rio Grande no Norte, em 2016, foi de RS 12.000,007. Depreende-se que a relação entre os

\footnotetext{
${ }^{6}$ Em 2016 a CONFEBRAQ já atingia seu XII Festival anual, que ocorre de forma itinerante e reúne grupos de todo o país.

7 Promovido pelo Governo do Estado do Rio Grande no Norte, com premiação para grupos estilizados e tradicionais: R\$ 12 mil, R\$ 8 mil e R\$ 5 mil (com dedução de impostos). Fonte: http://www.rn.gov.br/Conteudo.asp?TRAN=ITEM\&TARG=81461\&ACT=\&PAGE=\&PARM=\&LBL=Mater ia\#sthash.UFjPETbe.dpuf.
} 
grupos, instituições e pessoas exteriores aos grupos é fundamental na busca de apoio financeiro, financiamentos e patrocínios.

Esta trama, que já foi comparada a uma filigrana em outros trabalhos (Chianca, 2009) se compõe de relações entretecidas a partir de níveis não hierarquizáveis qualitativamente, mas desenhados em função das relações de interação do grupo de quadrilha de competição com a sociedade envolvente, onde os atores mais próximos do núcleo de poder do grupo (seus coordenadores) se afastam das redes próximas e imediatas, buscando outros grupos e personalidades da cidade, constituindo deste modo suas redes especializadas e externas. entrelaçamento deste tecido torna possível a composição de infinitos desenhos a partir dos primeiros delineamentos da sua urdidura, considerando sempre o pertencimento sócioeconômico dos seus integrantes, a sua origem (se é da capital ou de uma cidade menor), suas escolhas estéticas e políticas, a qual bairro pertence, e dentro deste qual o seu território e sua identificação mais local. É nesse sentido que a agência do grupo ganha sentido:

"Por um lado, o agente sempre está inserido em relações de (pretensa) solidariedade - família chegada, amigos, parentes, esposos/companheiros, filhos, pais, professores, padrinhos, e assim por diante. (...) Por outro lado, o agente está sempre enredado em relações de poder, de desigualdade, de competição e assim por diante" (ORTNER, 2007, p. 47).

Embora façam referência ao mundo rural projetando-o em seu cotidiano, são estes filhos da cidade quem decidem sobre suas escolhas: que representação do rural apresentar para o público? E quem são eles? "Geralmente a juventude, grupo etário, contribui ativamente para essa rápida assimilação das coisas e representações oriundas da cidade. [...] Isso são trivialidades sociológicas que convém lembrar para mostrar suas implicações" (Lefebvre, 1991, p. 12).

Ainda no campo das "trivialidades sociológicas", destacamos que grupos de quadrilha de competição iniciam seus ensaios com antecedência aproximada de cinco meses - embora os coordenadores praticamente não suspendam suas atividades durante o ano todo. E mais: para ensaiar do mês de fevereiro até junho é preciso ser jovem - em nossa pesquisa quase todos dançarinos haviam entre 16 e 21 anos, 91\% deles estava no ensino fundamental e 90\% do grupo era de solteiros. Apenas 24 deles trabalhavam, dos quais 16 em atividades urbanas como atendente de escritório ou consultório, doméstica, decorador, manicure e office boy ${ }^{8}$.

São pessoas com muita dificuldade para executar financeiramente este projeto, até na parte que cabe a cada dançarino, ou seja: sua própria vestimenta e acessórios. O grupo e

\footnotetext{
${ }^{8}$ Junto ao grupo de quadrilha Arraial Filhos da Mãe, de Mãe Luiza, do qual 69 (num total de 80 ) dançarinos responderam voluntária e benevolamente um questionário.
} 
cada um deve se organizar muito bem, e essa gestão não diz respeito unicamente ao período festivo, sendo também relativa ao cotidiano, refletindo o desejo coletivo de

"Fazer alguma coisa: elas gostariam de sentir essa coisa em suas mãos e vê-la surgir de sua atividade. Talvez essa exigência de uma obra seja destinada a desaparecer simultaneamente a certo humanismo, mas por enquanto ela parece ainda extremamente poderosa e este investimento de que eu falo é a procura de algo a se apropriar por meio de um esforço" (Lefebvre, 1970, p. 204) ${ }^{9}$.

Podemos afirmar que as disputas entre grupos de competição, os "grupos rivalizam no amor por sua cidade" (Lefebvre, 1991, p. 06), reanimando as suas identificações e aproximações e estimulando as suas concorrências e rivalidades: grupos de diversos bairros, setores e pedaços apresentam a cidade na sua fragmentação e totalidade. Cada um e todos representam seu local de origem, seu pertencimento e sua identidade:

"Esses concursos são ocasiões excepcionais de circulação de imagens e dos projetos estéticos, políticos e culturais- de cada grupo que, através deles, têm acesso a uma visibilidade social mais ampla, seja pela transmissão ao vivo do evento, seja por meio de uma publicidade ou matéria de jornal televisivo" (Chianca, 2013a, p. 234).

Nesta exposição espetacular, as quadrilhas de concursos revelam a dialética entre valor de uso e valor de troca na festa junina, pois se localizam no limiar entre

"a mobilização da riqueza [...] e o investimento improdutivo na cidade, entre a acumulação do capital e sua dilapidação nas festas, entre a extensão do território dominado e as exigências de uma organização severa desse território em torno da cidade dominadora" (Lefebvre, 1991, p. 06).

No caso da festa junina contemporânea no Nordeste, permeada por concursos de quadrilha promovidos por grandes redes de televisão em festas juninas de cunho midiático e comercial, a tradição festiva mantém seu valor de uso manipulado pela comunidade restrita, pois a despeito das percepções das festas espetaculares de cunho "pessimista neofrankfurtiano", a espetacularização não "representa um mal definitivo às tradições festivas". Opor a tradição

"aos megaeventos espetaculares de hoje (...) facilmente conduz à mera constatação negativa e não propositiva, quando não leva ao moralismo teórico e ideológico. Ora, para a antropologia essa dimensão espetacular é um dos elementos da performance ritual, e não apenas a resultante da racionalização instrumental da festa empresarial atual" (Cavalcanti, 2013, p. 18).

Sabemos, no entanto, que nas grandes festas juninas contemporâneas urbanas a tradição se converte em valor de troca para consumo pelo conjunto da cidade, muitas vezes em não-lugares como shopping centers, estacionamentos e ginásios, tendo o público como espectador de uma festa que hibridiza as formas festivas da praça pública e da forma desfile ${ }^{10}$. Perceber as diversificações das experiências festivas contemporâneas não significa

\footnotetext{
${ }^{9}$ Tradução nossa.

10 Para Cavalcanti (2013, p. 15-16) podemos distinguir as festas pela forma, na "forma social desfile" e na "forma social praça pública", para ele "duas polaridades não excludentes. No primeiro caso, temos exemplos como os antigos corsos carnavalescos, os desfile cívicos e militares, os préstitos religiosos, que
} 
destituir uma em beneficio da outra, valorizando a forma tradicional em detrimento da forma comercial, pois valor de uso e valor de troca estão em permanente relação participando tanto da cidade quanto da festa capitalista.

As quadrilhas de competição nos oferecem a verificação da tese que há uma ou várias diversas festas dentro da festa, como destacou Costa (2006): a despeito da organização das etapas e ações que os grupos de quadrilhas de competição empreendem fazendo da cidade a sua obra, os festivais de quadrilha convertem esta tradição em valor de troca, com o qual o publico se identifica aplaudindo, dançando ou cantando, mas também visualizando marcas, slogans, publicidades. Os jurados dos concursos também participam desse processo, conferindo o valor da apresentação através de um resultado classificatório que inclui uma dimensão comercial superposta à fruição e ao prazer do público e equipes.

Se "a obra é valor de uso e o produto é valor de troca" (Lefebvre, 1991, p. 04) este processo não envolve a todos indiscriminadamente do mesmo modo: público, jurados, comerciantes, produtores, dançarinos e grupos das quadrilhas de competição se apropriam de modo desigual desse valor.

\section{TRADIÇÃO, DINHEIRO, VISIBILIDADE}

A tensão obra/produto, valor de uso e valor de troca não gera alienação nas quadrilhas de competição, ao contrário: ela conduz à reflexão sobre os desafios e custos da independência financeira, condição à qual almejam organizadores e dançarinos de quadrilha, sobretudo quando se trata das mídias e de membros da representação política localvereadores ou deputados estaduais.

De modo inequívoco, as equipes das quadrilhas de competição se ressentem de pelo menos três distanciamentos críticos que nos revelam como os grupos de quadrilha de competição resguardam-se a uma relativa distância da festa como valor de troca: 1) como posicionar sua agência entre o cotidiano e a visibilidade fugaz oferecida pelas televisões e outros poderosos promotores de concursos; 2) o resguardo do que eles nomeiam "tradição"

distinguem os participantes diretos da audiência que os observa. É um modelo espetacular por excelência, ou seja, constituído para ser visto e admirado, aplaudido e ovacionado. [...] No segundo caso, temos o confusional festivo do vaivém sugerido pela ideia da praça pública onde, mesmo existindo a rigor, pequenos desfiles de agremiações e de grupos avulsos de brincantes, não há uma nítida separação entre atores e espectadores, tratando-se de uma forma em princípio menos espetacular do que a anterior, e com esses papéis grandemente comutáveis. E em que pese também consistirem curtos trajetos, quase sempre tomam forma mais espiralada, circular, em torno de uma área precisa, uma praça ou um quarteirão, diferentemente do sentido retilíneo unidirecional dos circuitos da forma desfile". 
(as identidades do grupo, da dança e da festa); 3) o temor pela "sujeira" do dinheiro oriundo do exterior do grupo.

Não esqueçamos que - salvo raríssimas exceções - os grupos de quadrilha são mais numerosos em setores urbanos com população sócio-economicamente desfavorecida, fundados sobre trajetórias pessoais onde o trabalho, esforço e o sacrifício pessoal não resultam necessariamente em ascensão social e econômica. Nestes grupos subsiste uma relação direta entre a pobreza (e o valor de uso) e a boa conduta moral, por um lado e de outro lado, o dinheiro (associado ao mercado, e ao valor de troca) e a riqueza ilícita, ou seja, uma conduta moral duvidosa. A desconfiança pesa sobre qualquer sinal repentino de riqueza, temido como um sintoma eventual de fraqueza moral, talvez criminosa: até mesmo o aporte pontual de um prêmio ou um financiamento conquistado a duras penas acende a centelha da dúvida no coletivo.

Nas quadrilhas de competição, o dinheiro e sua manipulação são uma presença previsível e os prêmios desejados. Mesmo assim eles são vistos com suspeição, como uma "sujeira", tal qual lembrou um dos dirigentes de um grupo lamentando certos rumores internos quando foram premiados em um concurso. Segundo ele, imediatamente no seio do próprio grupo começou: "entrou dinheiro, não sei o que lá...". Ao invés de consolidar o grupo, os recursos geram discórdia e desconfiança: "quem vai e como vai gastar?".

Assim a reciprocidade presente tanto no valor de uso próprio à fruição (aos gastos e ao desperdício), assim como no valor de troca inerente aos ganhos (das vitórias e de dinheiro), é dificilmente equacionada em termos de uma oposição excludente. Ela suscita uma tensão que se expressa claramente nos concursos promovidos pelas emissoras locais de televisão, muito valorizados pelos organizadores, dançarinos, equipes de apoio e torcedores, e, também, para o conjunto dos atores envolvidos na sua vasta rede. Nestas situações,

"enquanto os patrocinadores oferecem seus recursos por meio de cotas publicitárias, a televisão se encarrega de inscrever as quadrilhas e organizar a estrutura de apoio pela viabilização dos equipamentos urbanos propícios à concentração festiva" (Chianca, 2013b, p. 93).

Entretanto, este sistema escapa ao controle dos grupos que não conhecem o valor de cada uma das cotas dos patrocínios pagos à televisão, levando a especulação sobre tais valores, que correspondem (variavelmente segundo a fonte) em mais de $1.000 \%$ acima do valor do maior prêmio pago à melhor quadrilha. Assim os grupos problematizam o valor da obra que eles concedem gratuitamente à televisão, que pode divulgar trechos das apresentações dos grupos no festival ao vivo ou durante a sua programação diária. Há então a possibilidade de "aparecer na televisão", mesmo sem a almejada vitória no concurso promovido, meta de todos os participantes. A oportunidade (nem sempre realizada) de uma visibilidade maior, atingindo a totalidade da cidade -, através de uma imagem ou noticia positiva - convence o grupo de que está conduzindo uma participação negociada: 
"Divididos entre a construção de sua auto-imagem e de sua visibilidade, e a consciência inequívoca do potencial econômico das quadrilhas (cujo benefício thes escapa ao controle), os grupos experimentam as ambivalências inerentes à sua condição de estrelas e reféns dos concursos" (Chianca, 2013b, p. 93).

Outra preocupação de muitos líderes de quadrilhas de competição é que os espetáculos percam a tradição de vista, tradição significando aqui o conjunto das referências da festa junina e da dança da quadrilha, compartilhadas localmente e estreitando o vínculo simbólico entre diferentes grupos e gerações. Como seu principal patrimônio, a tradição tem valor de uso e troca nas transações simbólicas operadas na festa, e os grupos permanecem atentos à sua valorização, reconhecimento e renovação.

Se forem alienadas de seus atores, as quadrilhas podem inspirar outros interesses, até mesmo servir a grupos econômicos, mediáticos, do estado e de políticos - e já citamos a desconfiança que eles entretêm com os poderosos. Por isso, sua agência envolve o conjunto de seus participantes (dançarinos, coordenadores e técnicos ${ }^{11}$ ) na busca de superação das limitações, buscando uma autonomia criativa que permita realizar apresentações que satisfaçam a todos do grupo, ao público e, sobretudo aos jurados. Aqui, ganha importância a possibilidade de relação das quadrilhas com os poderosos, pois

\begin{abstract}
"A agência de poder (desigual), tanto da dominação como da resistência, pode ser contrastada com o segundo modo principal de agência anteriormente apontado: o de intenções, propósitos e desejos formulados em termos de "projetos" culturalmente estabelecidos. (...) Finalmente, é isto - uma agência de projetos - que os menos poderosos procuram alimentar e proteger ao criar ou proteger lugares, literal ou metaforicamente, "nas margens do poder" [...]. Muitos projetos, contudo, são "jogos sérios' plenamente desenvolvidos, envolvem o intenso jogo que multiplica sujeitos posicionados que perseguem metas culturais dentro de uma matriz de desigualdades locais e diferenciais de poder" (Ortner, 2007, p. 65).
\end{abstract}

Por isso o desafio principal dos grupos é desenvolver o conteúdo da dança sem romper a sua tradição - compreendida como "um conjunto de significados, símbolos e sentidos configurados de uma dada maneira, resultado da negociação sobre o que deve permanecer ao longo do tempo e aquilo que deve ser esquecido" (Albernaz, 2009, p. 15).

Trazemos a beleza da obra neste artigo porque a festa é aqui compreendida não como uma válvula de escape ou como esquecimento da realidade, tampouco como alienação, mas como consciência: para os dançarinos de uma quadrilha junina a festa é um momento de visibilidade, de afirmação identitária, de pertencimento local ou, corroborando com Henri

\footnotetext{
${ }^{11}$ Destacando que entre esse corpo técnico encontram-se os fundamentais estilistas, costureiros, sonoplastas, músicos, DJ's, maquiadores, cabelereiros, coreógrafos, aderecistas, cenografistas e outras especialidades que no caso de sucesso de um serviço com o grupo "acabam sendo considerados e se considerando do grupo" (Menezes Neto, 2009, p. 133), mesmo quando são profissionais.
} 
Lefebvre, de apropriação da cidade como obra: "o uso principal da cidade, isto é, das ruas e das praças, dos edifícios e dos monumentos, é a Festa" $(1991,04)$.

Parte crucial da vida urbana, a festa está situada no limiar das tensões entre o valor de uso e o valor de troca, entre a acumulação e a dilapidação do capital. Além destas tensões acima, a festa junina apresenta muitas outras, sendo uma das principais a sua incontestável importância para os citadinos, embora seja identificada na cidade como uma festa do mundo rural, uma festa "do interior".

Do ponto de vista performático, este imaginário recriado por ocasião da festa não constitui seu cotidiano, questão apontada entre outros por Marcos Souza (2010), analisando as festas juninas oficiais e publicitárias de Campina Grande (PB) e Caruaru (PE). Ele conclui serem ambas tentativas "de reviver um período rural no espaço urbano contemporâneo", ou seja; a busca de outro tempo na cidade de hoje.

Retomando as licenças e deslocamentos que o ritual possibilita, podemos compreender esta festa como a projeção de uma extraordinariedade simbólica constituída no fio das narrativas individuais, reminiscências e evocações de uma cosmologia rural, além das versões indiretas - como aquelas que conhecemos pelas mídias, também relevantes para uma recomposição simbólica citadina do rural.

Entre essas fontes, devemos destacar as memórias familiares muitas vezes ligadas a experiências migratórias do campo e pequenas cidades para cidades maiores. Tal memória é ao mesmo tempo intergeracional e dialógica, amalgamando um caleidoscópio de imagens (e sentimentos) identificados por vezes à cidade pequena, ao vilarejo, às aldeias, ao campo, à serra, à roça, ou ao mato. Este lugar urbano (o rural da cidade) é um "lugar de ontem", referência que se deseja recuperar (com precauções rituais) ou pelo menos recordar, na cidade.

É muito interessante escutar os atores das festas juninas, jovens majoritariamente nascidos e crescidos em grandes cidades, que dizem"12: "O que a gente bota na quadrilha junina são as pessoas que vivem em uma cidade pequena. Toda cidade pequena tem um carteiro, tem um delegado, um padre... Toda cidade pequena tem um juiz, tem um prefeito, tem uma cigana, os ciganos... Então o que a gente bota em uma quadrilha é a cidade pequena".

Como imaginação, lembrança ou nostalgia, a memória social da cidade pequena ou do meio rural constitui seus caminhos na festa junina urbana, pois ela é um tempo de copiosas trocas e intensa sociabilidade constituindo uma sintaxe particular: "a cidade é uma linguagem,

\footnotetext{
${ }^{12}$ As quadrilhas juninas são uma dança própria das festas deste período, apresentada em outros trabalhos como Chianca (2013a), Menezes Neto (2009) e Almeida \& Lelis (2004). Esta fala é oriunda de uma entrevista concedida na cidade de Natal (RN).
} 
uma escritura, mais exatamente. Ela escreve algo; ela escreve diante de nós um conjunto vivido, memorizado e imaginado" (Lefebvre, 1970, p. 202) ${ }^{13}$.

Para compreender esse conjunto, não nos interessa pensar o rural e o urbano como duas realidades excludentes: Souza (2010) e Chianca (2013a) já denunciaram o esvaziamento provocado por esta falsa dicotomia na festa junina, pois o rural persiste e age no urbano. Ambas as categorias contribuem para pensar esses dois territórios (e temporalidades), lembrando que "o passado, para quem não o analisa, freqüentemente se perde, se dissolve num presente perfeitamente presente e aparentemente dado, ou num só bloco anacrônico e ultrapassado" (Lefebvre, 1970, p. 22) ${ }^{14}$.

É preciso dizer que o contexto que apresentamos nesse artigo é o de Natal, cidade capital política, administrativa e econômica do estado do Rio Grande do Norte. Grande pólo de atração demográfica, Natal se urbanizou muito recentemente, conhecendo um crescimento populacional impressionante a partir dos anos $1950^{15}$. Assim, grande parte de sua população tem pais ou avós migrantes, quando não é oriunda diretamente de uma cidade do interior do estado. Existe, portanto, uma grande identificação da população com o rural, seja ele uma cidade menor, um roçado ou um sítio.

Quando desejamos definir fronteiras identitárias, podemos nos identificar com inúmeras referências, sendo a migração uma delas, e não a mais evidente, pois apesar de atrelar-se a uma identidade de origem, a dinâmica sócio-econômica da migração no século XX em Natal é marcada por uma profunda distância entre as motivações gerando a iniciativa migratória e suas efetivas possibilidades de sucesso ${ }^{16}$. Encontramos ali diversos relatos de migração dolorosos e sofridos que precisaram ser reorganizados individual e coletivamente (nos planos psicológicos e simbólicos), revelando como "a relação urbanidade-ruralidade não desaparece; pelo contrário, intensifica-se, e isto mesmo nos paises mais industrializados. Interfere com outras representações e com outras relações reais: cidade e campo, natureza e facticidade, etc". (Lefebvre, 1991, p. 12).

Em muitos casos a festa ofereceu uma excelente oportunidade para reconstituir e superar essas experiências de deslocamento, como revelam as vestimentas juninas, que

\section{Tradução do autor.}

14 Tradução do autor.

15 Em 1920 Natal contava 30.696 habitantes. Trinta anos depois eram 103.915 habitantes. Em 1980 tinha 428.721 habitantes e em 2016 estima-se em 877.662. Consultados a 17/05/2017 em https://www.ibge.gov.br/home/estatistica/populacao/sinopse_preliminar/Censo2000sinopse.pdf e http://cidades.ibge.gov.br/xtras/perfil.php?lang=\&codmun=240810\&search=rio-grande-donorte|natal

16 Souza, 1980.

137 
marcam uma experiência de reforço seguida de superação desta memória marginalizada (Pollak,1989), quando

"vestimentas de pais e avós são publicamente recuperadas, sendo que tal recurso valoriza a qualidade da fantasia de matuto. [...] Retomar as roupas de família parece ser um modo de recuperar sua identidade de migrante a fim de melhor ultrapassá-la no contexto derrisório da festa. Sem exaltar essa identidade pré-migratória, o ritual permite que ela seja re-experimentada, para ser em seguida desdenhada- assim como a esse passado definitivamente abandonado" (Chianca, 2013a, p 79 e ss).

A presença dos temas "tradição, dinheiro e visibilidade" nos grupos de quadrilha de competição nos conduz à conclusão que os grupos vêm agenciando sua permanência no cenário festivo, representando as buscas cotidianas dos grupos de quadrilhas, que constroem sua dança sobre um valor de uso (a tradição e a memória), buscando recursos e visibilidade para seu projeto, que emerge como resistência às relações de poder cotidianas.

Hoje intensamente presentes, os modelos comerciais da festa dividiram sua temporalidade e espacialidade com os modelos populares ao longo de todo o século XX e no século XXI, cabendo destacar que, apesar de serem grupos de competição perfeitamente inseridos num circuito comercial e espetacular da festa junina, eles não descartam os laços e vínculos pessoais e afetivos que presidem seu cotidiano, guardando a possibilidade de combinar o produto (seu espetáculo) com o valor de uso associado à fruição e à festa.

É necessário salientar ainda que a quadrilha de competição não pode ser compreendia por um víeis unívoco: ela não se converte necessariamente em produto porque participa de uma experiência comercial, midiática e espetacular. O "puro valor de uso" de que fala $H$. Lefebvre está presente neste tipo de quadrilha, quando todos ensaiam, se apresentam no bairro, passeiam, se divertem ou convivem juntos. Assim os jovens dançarinos formam grupos que se reúnem nos ensaios e apresentações, mas também no dia a dia da escola: no pátio durante os intervalos ou para percorrerem o caminho juntos no retorno da escola para suas casas.

Como afirma Souza (2010, p. 118-119): "mais que berço da alienação moderna, o cotidiano é também (...) território a partir do qual a participação pode surgir". Graças à experiência urbana esse mesmo grupo conhece o valor de troca incorporado a seus ensaios e apresentações - convertidas em espetáculos - e constitui ciclos de reciprocidade envolvendo outros grupos de quadrilha, lideranças de bairro, associações, amigos, familiares e vizinhos, apoios políticos e técnicos.

Consideremos ainda que o universo quadrilheiro (de grupos de quadrilha) tem uma realidade bastante fragmentada entre as centenas de grupos que há no Nordeste. Assim como a festa junina que pode ser experimentada de incontáveis maneiras, os bairros são 
realidades diversas a ponto de se necessitar relativizá-los 17 em cidades também fragmentadas, ordinariamente complexas e divididas entre bairros ricos e pobres, antigos ou recentes, centrais ou periféricos. Deles emergem as quadrilhas, que ritualizam rivalidades e bairrismos 18 em concursos supostamente igualitários nos quais a justiça e a eqüidade parecem reinar para que "vença a melhor", instituindo ritualmente e simbolicamente a cidade como uma totalidade coerente, organizada e regulada.

Estamos falando também de fragmentações que incorporam a crítica sempre presente da Igreja católica com seus setores mais conservadores: "Essa é uma festa católica! Não se pode transformar uma festa católica em uma festa para tomar cachaça, para dançar!". Ou o discurso de muitos intelectuais conservadores, sempre avaliando moralmente a quadrilha de competição: "Isso nem é mais quadrilha, se tornou uma dança qualquer!". Neste viés a quadrilha de competição também experimenta uma situação desconfortável:

"enquanto os conservadores a recusam como 'degradação da tradição', os intelectuais da esquerda denunciam sua natureza 'massificada', seus promotores como 'cúmplices', e seus praticantes como 'vitimas da alienação cultural'"(Chianca, 2013a, p. 83).

Se o rendilhado da trama confere autenticidade e originalidade a cada quadrilha assim como a cada peça de filigrana, isso se deve aos "violentos contrastes entre a riqueza e a pobreza, os conflitos entre os poderosos e os oprimidos [que] não impedem nem o apego à Cidade, nem a contribuição ativa para a beleza da obra" (H. Lefebvre, 1991: 05). Entretecida na vida social na cidade, os grupos de quadrilha de competição oferecem um belo, complexo e elucidativo campo para a compreensão da cidade na sociedade capitalista, com suas agências e obras.

\section{REFERÊNCIAS:}

ALBERNAZ, Lady Selma Ferreira. Estéticas e disputas em torno do bumba-meu-boi (São Luís, Maranhão). Revista Anthropológocas, 21(1), 77-97, 2010.

\section{ALBERNAZ, Lady Selma Ferreira. Prefácio. In: 0 balancê no arraial da capital: quadrilha e} tradição no São João do Recife. Recife: Ed do Autor, 2009. p.13-18, .

ALMEIDA, Magdalena; Lélis, Carmem. Quadrilha junina historia e atualidade: movimento que não é só imagem. Recife: Prefeitura da Cidade do Recife, 2004.

\footnotetext{
17 O que procuram Magnani \& Torres (1996), com a categoria pedaço ou ainda Costa (1999) destacando os limites da "visibilidade exarcebada" inscrita aos bairros.

${ }^{18}$ No sentido que the atribui Cordeiro (1997): como "rivaliade(s) quotidiana(s) permitindo a visibilidade de uma segmentação interna" (p. 24). 
BERGER, Peter; LUCKMAN, Thomas. A Construção Social da Realidade. Petrópolis: Editora Vozes. [7ª edição], 1987.

CAVALCANTI, Bruno César. Novos lugares da festa: tradições e mercados. Revista Observatório Itaú Cultural, OIC, n. 14, 10-20, 2013.

CHIANCA, Luciana. São João na cidade: ensaios e improvisos sobre a festa junina. João Pessoa: Editora UFPB, 2013a.

CHIANCA, Luciana. 0 auxílio luxuoso da sanfona: tradição, espetáculo e mídia nos concursos de quadrilhas juninas. Revista Observatório Itaú Cultural: OIC, 14, 89-100, 2013b.

CHIANCA, Luciana. As filigranas da sociabilidade urbana: reciprocidade, hierarquia e redes sociais. Anais do $33^{\circ}$ Encontro Anual da ANPOCS, 2009.

CHIANCA, Luciana. Famosos, mas pobres: redes e projeto num grupo "urbano" de dança "rural". Anais do $32^{\circ}$ Encontro Anual da ANPOCS, 2008.

CHIANCA, Luciana. A festa do interior: São João, migração e nostalgia em Natal no século XX. Natal: Editora UFRN, 2006.

CORDEIRO, Graça Indias. Um Lugar na Cidade. Lisboa: Don Quixote, 1997.

COSTA, Antônio Mauricio Dias da. A Festa dentro da Festa: Recorrências do modelo festivo do circuito bregueiro no Círio de Nazaré em Belém do Pará. Campos, 7(2): 83-100, 2006.

COSTA, Antonio Firmino da. Sociedade de bairro. Oeiras: Celta, 1999.

DA MATTA, Roberto. Carnavais, Malandros e Heróis: para uma sociologia do dilema brasileiro. Rio de Janeiro: Zahar Editores, 1983.

LEFBVRE, Henri. 0 direito à cidade. São Paulo: Editora Moraes Ltda, 1991.

LEFEBVRE, Henri. Du ru ral à l'urbain. Paris : Éditions Anthropos, 1970.

LEFEBVRE, Henri. Le droit à la ville. L'Homme et la société, 6:29-35, 1967.

MAGNANI, José G. Cantor; TORRES, Lilian de Lucca (Orgs.). Na Metrópole. São Paulo: Edusp/Fapesq, 1996.

MENEZES NETO, Hugo. 0 balancê no arraial da capital: quadrilha e tradição no São João do Recife. Recife: Ed do Autor, 2009.

MORICE, Alain. Reestruturação política do mercado habitacional e rotatividade da mão-de-obra na construção civil em João Pessoa (PB). Política e trabalho, n. 7, 33-48, 1999.

ORTNER, Sherry B. "Poder e Projetos: Reflexões sobre a agência". In: GROSSI, Miriam Pillar; ECKERT, Eckert; FRY, Peter Henry Fry (Orgs.). Conferências e práticas antropológicas. Blumenau: Nova Letra, 2007. 
POLLAK, Michael. Memória, Esquecimento, Silêncio. Estudos Históricos, v. 2, n. 3, 3-15, 1989.

SOUZA, Itamar de. Migrações internas no Brasil. Natal: Fundação José Augusto/Vozes, 1980.

SOUZA, Marcos Felipe Sudré. A Festa e a Cidade: Experiência coletiva, poder e excedente no espaço urbano. Belo Horizonte: Escola de Arquitetura da UFMG, 2010.

Recebido em 08 de julho de 2018.

Aprovado em 06 de dezembro de 2018. 